\title{
AWARENESS ABOUT DIABETIC RETINOPATHY AMONG DIABETIC PATIENTS IN RURAL AREA OF CENTRAL KERALA
}

\author{
Nirmala Prabhakar1, Ann Mary Thomas², Gopalakrishnan Padmanabhan³, Harsha Chollankil Hariharan ${ }^{4}$, Swati Londhe ${ }^{5}$, \\ Devaki Antharjanam6, Raju Antony ${ }^{7}$
}

\begin{abstract}
${ }^{1}$ Associate Professor, Department of Ophthalmology, Sree Narayana Institute of Medical Sciences, Chalakka.
${ }^{2}$ Assistant Professor, Department of Community Medicine, Sree Narayana Institute of Medical Sciences, Chalakka.

${ }^{3}$ Associate Professor, Department of Community Medicine, Sree Narayana Institute of Medical Sciences, Chalakka.

${ }^{4}$ Assistant Professor, Department of Biostatistics, Sree Narayana Institute of Medical Sciences, Chalakka.

5 Professor, Department of Community Medicine, Sree Narayana Institute of Medical Sciences, Chalakka.

${ }^{6}$ Assistant Professor Department of Community Medicine, Sree Narayana Institute of Medical Sciences, Chalakka.

${ }^{7}$ Professor and HOD, Department of Community Medicine, Sree Narayana Institute of Medical Sciences, Chalakka.
\end{abstract}

\begin{tabular}{l} 
ABSTRACT \\
\hline BACKGROUND \\
Meta-analysis from 35 studies from 1980 to 2008 showed that global prevalence of Diabetic Retinopathy was $34.6 \%$. Major risk \\
factors of diabetic retinopathy are poor glycaemic control, duration of diabetes and associated hypertension. Regular eye checkup is \\
mandatory for early detection of Diabetic Retinopathy and prevention of blindness. This study is aimed at finding out the knowledge \\
about Diabetic Retinopathy among diabetic patients in a rural area of Central Kerala.
\end{tabular}

\section{MATERIALS AND METHODS}

Data collected using a pretested semi-structured questionnaire containing questions to assess the knowledge along with demographic details.

STUDY DESIGN- Observational cross sectional study of diabetic patients selected by random sampling method.

\section{RESULTS}

A total number of 410 diabetic people from rural area were included in the study. Out of this, 28 (6.8\%) had no knowledge about Diabetic Retinopathy and 316 (77.07\%) patients had good knowledge. 242 (59.02\%) had undergone eye checkup to rule out Diabetic Retinopathy. Significant association between duration of diabetes and good knowledge (p value-0.046) was found. But no significant association between gender and knowledge was found. 32.4\% were unaware that Diabetic Retinopathy depends on duration of the disease and 24\% did not know that Diabetic Retinopathy leads to blindness. Major sources of information were mass media (48\%) and hospital/camps (41\%).

\section{CONCLUSION}

Good knowledge can be attributed to the high literacy rate, but only a few knew that duration and heredity are major risk factors. This emphasises the need of conducting health education/awareness classes on a regular basis.

\section{KEYWORDS}

Knowledge, Awareness, Non-Insulin Dependent Diabetes Mellitus (NIDDM), Rural Area, Diabetes, Diabetic Retinopathy (DR).

HOW TO CITE THIS ARTICLE: Prabhakar N, Thomas AM, Padmanabhan G, et al. Awareness about diabetic retinopathy among diabetic patients in rural area of central Kerala. J. Evolution Med. Dent. Sci. 2016;5(79):5874-5877, DOI: 10.14260/jemds/2016/1325

\section{BACKGROUND}

Non-insulin-dependent Diabetes Mellitus (NIDDM) is a life style disorder which is commonly seen after the age of $40 \mathrm{yrs}$ In a literate state like Kerala, there is no sharp demarcation in the lifestyle of rural and urban population. As a result prevalence of NIDDM is on the rise in the rural population as well.

Financial or Other, Competing Interest: None.

Submission 27-08-2016, Peer Review 19-09-2016,

Acceptance 26-09-2016, Published 01-10-2016.

Corresponding Author:

Dr. Nirmala Prabhakar

12/561 Sriniketan,

Pandikudy,

Kochi- 682002.

E-mail:nimma.prabhu@gmail.com

DOI: $10.14260 /$ jemds/2016/1325
A study on global prevalence and major risk factors on Diabetic Retinopathy(DR) conducted by Yau J et al showed that the global prevalence of any type of DR was $34.6 \%$ as found by meta-analysis from 35 studies from 1980 to 2008 . The study showed that prevalence of proliferative diabetic retinopathy was $6.96 \%$ and diabetic maculopathy was $6.81 \%$. It was also highlighted that the major risk factors for DR are duration of diabetes, poor glycaemic control and associated systemic hypertension. ${ }^{[1]}$ In a study conducted by P.K. Rani et al in urban and rural populations of 3 states of South India, it was found that prevalence of DR was slightly more among rural population $(18 \%)$ than urban population (17\%). A similar pattern of prevalence is seen in case of referable retinopathy (6.8\% in rural and $4.6 \%$ in urban population). Surprisingly, more subjects belonging to rural population had done DR screening than the urban population.[2] The prevalence of DR was found to be $10.4 \%$ in rural India in a study conducted by Rajive Raman et al. It was also found that prevalence of DR was $10.3 \%$ among the diabetics. Male gender, use of insulin, longer 
duration of diabetes ( $>15$ yrs.), poor glycaemic control and associated systemic hypertension were found to be the high risk factors. [3]

Chengamanad Diabetic Retinopathy Awareness Study (CDRAS) conducted at Chengamanad (Ernakulam District, Kerala) by Mahesh et al also reported lack of awareness and lack of knowledge about DR among the rural population. [4]The study conducted by Cetin EN et al emphasised the importance of good control of DR and regular eye checkup in the prevention of DR. They also found that even though most of the patients are aware of DR, they lack appropriate knowledge and behaviour about the management of DR.[5] Earlier studies conducted in Australia found that only $37 \%$ of the patients with diabetes mellitus were aware of this disease. ${ }^{6]}$ whereas a study from the U.S. found that $65 \%$ of people with diabetes were aware of the association between diabetes and eye disease.[7] In a study by Dandona et al on urban general population in India, the prevalence of DR was high but a low level $(27.0 \%)$ of awareness about this dreaded complication was observed. ${ }^{[8]}$ The aim of this study was to find out the awareness and knowledge of DR in the rural population of a literate state like Kerala.

\section{MATERIALS AND METHODS}

Approval was obtained from institutional research and the ethics committee. Initially, a questionnaire was prepared in local language and applied on 30 diabetic patients attending the diabetic clinic of our hospital. Necessary modifications were made and it was finalised. This finalised questionnaire was distributed to 167 Anganwadi workers after explaining the full details to them. The Anganwadi workers were asked to distribute this questionnaire along with the consent form to all willing patients with Diabetes in their area. Questionnaire contained information regarding demographic details, duration of diabetes, frequency of glycaemic control, frequency of eye checkup, family history of diabetes, few questions to assess the knowledge about diabetic retinopathy and the source of information on DR .The patients were instructed to return the filled answer sheets immediately to the Anganwadi worker. Data were analysed using the software SPSS version 15. Mean, standard deviation, frequency and percentage were calculated. Chi-square test was done to find out the association between knowledge on DR and various factors. $p<0.05$ was considered as statistically significant.

\section{RESULTS}

A total of 410 patients with diabetes who gave consent were included in this study. Out of this, 176(42.9\%) were males and 234(57.1\%) were females. Mean age of the study participants was 58.6 years and standard deviation 11.4 years. All these 410 patients were literate and they were above the age of 30 years. Based on the duration of diabetes, patients were divided into 2 groups; one with duration $<5$ years - 261(63.7\%) and another with duration $>/=5$ years -149 (36.3\%).

Based on education, they were grouped into 3; group I, up to $10^{\text {th }}$ standard - 192(46.8\%); group II, plus two and diploma - 182(44.4\%); group III, graduate and postgraduate 36(8.8\%). Depending on the scores obtained they were divided into 2 ,> $50 \%$ (good knowledge) and $</=50 \%$ (poor knowledge).

No positive family history in 142 patients (34.6\%), but 268 $(65.36 \%)$ had a positive family history. Blood tests were done at a frequency of 1-2 months in 226(55.1\%) patients, 6 months in $134(32.7 \%)$ patients, $>6$ months in $50(12.2 \%)$ patients.

Out of this 410 patients, $242(59 \%)$ had undergone eye checkup to rule out eye disease, but 168 (41\%) did not. $42(10.2 \%)$ gave family history of diabetic eye disease.

\begin{tabular}{|c|c|c|c|c|}
\hline Duration & $\begin{array}{c}\text { Poor } \\
\text { Knowledge }\end{array}$ & $\begin{array}{c}\text { Good } \\
\text { Knowledge }\end{array}$ & Total & $\begin{array}{c}\text { p } \\
\text { Value }\end{array}$ \\
\hline <5 Years & $\begin{array}{c}68 \\
(26.1 \%)\end{array}$ & $\begin{array}{c}193 \\
(73.9 \%)\end{array}$ & $\begin{array}{c}261 \\
(100 \%)\end{array}$ & \multirow{2}{*}{0.046} \\
\cline { 1 - 4 }$>/=5$ & 26 & 123 & 149 \\
$(82.6 \%)$ & $(100 \%)$ & \\
Years & $(17.4 \%)$ & $\mathbf{9 1 0}$ & \\
\hline Total & $\mathbf{9 4}$ & $\mathbf{3 1 6}$ & $\mathbf{4 1 0}$ & \\
\cline { 1 - 3 } Table 1: Relation between duration of Diabetes and \\
Knowledge on Diabetic Retinopathy \\
\hline
\end{tabular}

Among the patients with duration of diabetes $<5$ years, 193 (73.9\%) had good knowledge and those with duration $>/=5$ years, $123(82.6 \%)$ had good knowledge. This difference was statistically significant $(\mathrm{p}=0.046)$.

\begin{tabular}{|c|c|c|c|c|}
\hline Gender & $\begin{array}{c}\text { Poor } \\
\text { Knowledge }\end{array}$ & $\begin{array}{c}\text { Good } \\
\text { Knowledge }\end{array}$ & Total & $\begin{array}{c}\text { P } \\
\text { Value }\end{array}$ \\
\cline { 1 - 4 } Male & $\begin{array}{c}41 \\
(23.3 \%)\end{array}$ & $\begin{array}{c}135 \\
(76.7 \%)\end{array}$ & $\begin{array}{c}176 \\
(100 \%)\end{array}$ & \multirow{2}{*}{0.0878} \\
\cline { 1 - 4 } Female & $\begin{array}{c}53 \\
(22.6 \%)\end{array}$ & $\begin{array}{c}181 \\
(77.4 \%)\end{array}$ & $\begin{array}{c}234 \\
(100 \%)\end{array}$ & \\
\cline { 1 - 4 } Total & 94 & 316 & 410 & \\
\cline { 1 - 3 } Table 2: Comparison of Gender and Knowledge on \\
\multicolumn{4}{|c|}{ Diabetic Retinopathy } \\
\hline
\end{tabular}

Males 135 (76.7\%) and females 181 (77.4\%) had good knowledge. So this is not statistically significant $(\mathrm{p}=0.0878)$.

\begin{tabular}{|c|c|c|c|}
\hline \multirow{2}{*}{ Question Asked } & \multicolumn{3}{|c|}{ Response Given } \\
\cline { 2 - 4 } & Yes & No & $\begin{array}{c}\text { Don't } \\
\text { Know }\end{array}$ \\
\hline $\begin{array}{c}\text { Diabetes affects the } \\
\text { retina causing diabetic } \\
\text { retinopathy }\end{array}$ & $\begin{array}{c}295 \\
(72.0 \%)\end{array}$ & $\begin{array}{c}18 \\
(4.4 \%)\end{array}$ & $\begin{array}{c}97 \\
(23.7 \%)\end{array}$ \\
\hline $\begin{array}{c}\text { Diabetic retinopathy } \\
\text { results in blindness. }\end{array}$ & $\begin{array}{c}305 \\
(74.4 \%)\end{array}$ & $\begin{array}{c}6 \\
(1.5 \%)\end{array}$ & $\begin{array}{c}99 \\
(24.1 \%)\end{array}$ \\
\hline $\begin{array}{c}\text { Diabetic retinopathy } \\
\text { depends on duration of } \\
\text { diabetes. }\end{array}$ & $\begin{array}{c}243 \\
(59.3 \%)\end{array}$ & $\begin{array}{c}34 \\
(8.3 \%)\end{array}$ & $\begin{array}{c}133 \\
(32.4 \%)\end{array}$ \\
\hline $\begin{array}{c}\text { Diabetic retinopathy } \\
\text { can be prevented by } \\
\text { controlling blood sugar. }\end{array}$ & $\begin{array}{c}318 \\
(77.6 \%)\end{array}$ & $\begin{array}{c}18 \\
(4.4 \%)\end{array}$ & $\begin{array}{c}74 \\
(18 \%)\end{array}$ \\
\hline $\begin{array}{c}\text { Effective treatment } \\
\text { available for diabetic } \\
\text { retinopathy }\end{array}$ & $\begin{array}{c}316 \\
(77.1 \%)\end{array}$ & $\begin{array}{c}24 \\
(5.9 \%)\end{array}$ & $\begin{array}{c}70 \\
(17 \%)\end{array}$ \\
\hline \multicolumn{2}{|c|}{ Table 3: Knowledge on Diabetic Retinopathy } \\
\hline
\end{tabular}

Around $70 \%$ of people gave the right response to all the questions and around 25\% were not aware of the disease. 


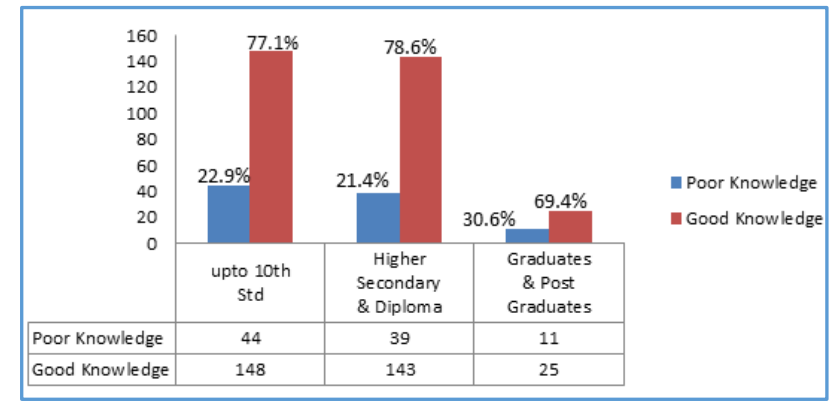

Fig. 1: Comparison - Educational Status \& Knowledge on Diabetic Retinopathy

Level of education has no relation with awareness and knowledge. $p=0.492$ (Not significant).

\section{Source of awareness}

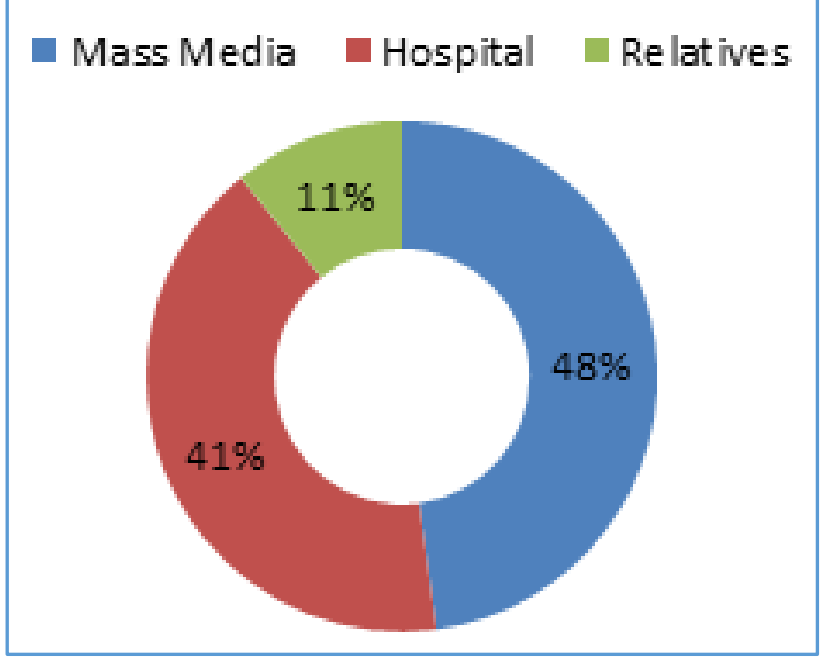

Fig. 2: Source of Awareness on Diabetic Retinopathy

Most of them got information from mass media and hospital.

\section{DISCUSSION}

Diabetic retinopathy constitutes $4.8 \%$ of blindness globally. Blindness due to diabetic retinopathy is irreversible, but it can be prevented if detected at an early stage. It is lack of awareness and lack of knowledge of this disease is preventing people to undergo screening procedures. In the present study, among 410 diabetic patients $28(6.8 \%)$ had no knowledge about DR and 316(77.07\%) patients had good knowledge, $242(59.02 \%)$ had undergone eye checkup to rule out DR. Study conducted by Mahesh et al reported that out of 1096 diabetic patients, 713 were aware of DR.[4] Another study conducted in a rural population in South India by P. K. Rani et al found that $37.1 \%$ out of 1938 had knowledge about DR .Among this those who speak Malayalam language and those who belong to upper socioeconomic status had a significantly better awareness regarding DR. Those who had knowledge showed positive attitude towards screening.[9]

A hospital based study conducted in Nigeria revealed that out of 185 patients $84.3 \%$ were aware about DR but only 15.7\% had undergone DR screening.[10] A similar study conducted in Kenya, a developing country revealed that $83 \%$ were aware of diabetic eye disease but only $50 \%$ went for eye checkup.[11] Yet another study conducted in Malaysia, a developed country showed $87.2 \%$ patients were aware but < $50 \%$ had undergone ocular examination. ${ }^{[12]}$

In our study, no significant association was found between gender and the level of knowledge. Other studies also showed no gender difference in the level of knowledge.[13]

Family history was positive in $268(65.36 \%)$ patients and 42 (10.2\%) had diabetic eye disease.

Our study revealed a significant association between duration of diabetes and good knowledge. $82.6 \%$ of patients with duration of diabetes $>/=5$ years had good knowledge whereas no significant association was found between the level of education and knowledge. Study conducted at other places also revealed significant relation between duration and knowledge.[14,15,16]

In the present study, about $70 \%$ gave correct response to the questions to assess the knowledge and about $25 \%$ were not aware of the disease. Studies conducted at Colombo showed only $31 \%$ having good knowledge.[14] Ramiz Hussain et al reported $619(40.7 \%)$ out of 1538 patients with diabetes mellitus to have good knowledge of the disease[15,16]. In our study, 32.4\% were unaware that DR depends on duration of the disease and $24 \%$ did not know that DR leads to blindness. Population based study conducted by Mahesh e al reported that 479 patients (43.7\%) knew that frequent ocular examinations are necessary and 674 patients $(61.5 \%)$ did not know that the duration of the disease had any relation with diabetic retinopathy.

In the present study, we found mass media (48\%) and hospital/camps (41\%) as the major sources of information. The study conducted by Saikumar et al reported that $36 \%$ diabetic patients who were aware of DR gained knowledge through the mass media, $32 \%$ from doctors. ${ }^{[17]}$ The study conducted in 2 diabetic centres at Glasgow and UK reported that they gained information from hospital staff.[18]

\section{CONCLUSION}

Majority of the people are having good knowledge about diabetic retinopathy, but only a few knew that duration of diabetes and heredity has a role in developing DR. This may prevent patients from visiting an ophthalmologist for diabetic retinopathy screening. In a developing country like India, financial burden for getting treatment for diabetic retinopathy is very high. Being a disease of socioeconomic concern, efforts to create awareness among the public about diabetic retinopathy are much needed. Awareness programs need to be conducted frequently so that blindness due to diabetic retinopathy can be avoided.

\section{ACKNOWLEDGEMENT}

I am grateful to the patients who participated in this study, Anganwadi workers who helped us to conduct this study, Child Development Project Officer, Parakkadavu Block Panchayath who gave consent to this study, HOD and Staff of Community Medicine Department for their support in this study.

\section{REFERENCES}

1. Yau JW, Rogers SL, Kawasaki R, et al. Global prevalence and major risk factors of diabetics retinopathy. Diabetes Care 2012;35(3):556-64.

2. Rani PK, Raman R, Sharma V, et al. Analysis of a comprehensive retinopathy screening model for rural and urban diabetics in developing countries. $\mathrm{Br} \mathrm{J}$ Opthal 2007;91(11):1425-9. 
3. Raman R, Ganesan S, Pal SS, et al. Prevalence and risk factor for diabetic retinopathy in rural India. Sankara Nethralaya diabetic retinopathy epidemiology and molecular genetic study III (SN-DREAMS III), report no 2. BMJ Open Diab Res Care 2014;2(1):e000005.

4. Mahesh G, Elias A, Sandhya N, et al. Chengamanad diabetic retinopathy awareness study (CDRAS). Kerala Journal of Ophthalmology 2006;18:14-21.

5. Cetin EN, Zencir M, Fenkçi S, et al. Assessment of awareness of diabetic retinopathy and utilization of eye care services among Turkish diabetic patients. Prim Care Diabetes 2013;7(4):297-302.

6. Livingston PM, Wood CA, McCarty CA, et al. Awareness of diabetic retinopathy among people who attended a diabetic retinopathy screening program. Med J Aust 1998;169(2):117.

7. Merz CN, Buse JB, Tuncer D, et al. Physician attitudes and practices and patient awareness of the cardiovascular complications of diabetes. J Am Coll Cardiol 2002;40(10):1877-1881

8. Dandona R, Dandona L, John RK, et al. Awareness of eye diseases in an urban population in southern India. Bulletin of the World Health Organisation 2001;79(2):96-102.

9. Rani PK, Raman R, Subramani S, et al. Knowledge of diabetes and diabetic retinopathy among rural populations in India, and the influence of knowledge of diabetic retinopathy on attitude and practice. Rural and Remote Health 2008;8(3):838.

10. Mohammed I, Waziri AM. Awareness of diabetic retinopathy amongst diabetic patients at the Murtala Mohammed hospital, Kano, Nigeria. Nigerian Medical Journal 2009;50(2):38-41.
11. Mwangi MW, Giyhinji CG, Githinji W. Knowledge and awareness of diabetic retinopathy amongst diabetic patients in Kenyatta national hospital. International Journal of Humanities and Social Science 2011;1(21): 140-6.

12. Addoor KR, Bhandary SV, Khanna R, et al. Assessment of awareness of diabetic retinopathy among the diabetics attending the peripheral diabetic clinics in Melaka, Malaysia. Med J Malaysia 2011;66(1):48-52.

13. Tajunisah I , Wong PS, Tan LT, et al. Awareness of eye complications and prevalence of retinopathy in the first visit to eye clinic among type 2 diabetic patients. Inter national Journal of Ophthalmol 2011.

14. Seneviratne B, Prathapa S. Knowledge on diabetic retinopathy among diabetes mellitus patients attending the Colombo south teaching hospital, Sri Lanka. Journal of US-China Medical Science 2016;13:35-46.

15. Hussain R, Rajesh B, Giridhar A, et al. Knowledge and awareness about diabetes mellitus and diabetic retinopathy in suburban population of a south Indian state and its practice among the patients with diabetes mellitus: a population based study. Indian $\mathrm{J}$ Ophthalmol 2016;64(4):272-276.

16. Koshy J, Varghese DL, Mathew T, et al. Study on KAP of ocular complications due to diabetes among type 2 diabetics visiting a tertiary teaching hospital. Indian Journal of community health 2012;24(1).

17. Saikumar SJ, Giridhar A, Mahesh G, et al. Awareness about eye diseases among diabetics-a survey in south India. Community Eye Health Journal 2005;18 (54):97.

18. Robertson JL, Akhtar S, Petrie JR, et al. How do people with diabetes access information? Practical Diabetes International 2005;22(6):207-210. 